\title{
Orientação Vocacional e Profissional em Moçambique: Percepções dos
}

\section{Actores Educativos}

\section{Vocational and Professional Orientation in Mozambique: Perceptions of Educational Actors}

\author{
Júlio Taimira Chibemo*, Fernando Canastra, ${ }^{* *}$ \\ Universidade Jean Piaget de Moçambique*, Universidade Católica de Moçambique,**
}

\begin{abstract}
Resumo
$\mathrm{O}$ presente artigo tem como enfoque principal dar conta das percepções de actores educativos, no contexto das instituições de ensino (secundário e superior), sobre o sentido de que se reveste a orientação vocacional e profissional. Este estudo foi realizado na Cidade da Beira (Moçambique), envolvendo as principais instituições do ensino secundário e das instituições do ensino superior. A orientação vocacional e profissional assume uma relevância significativa, considerando, por um lado, as incertezas e a mobilidade permanente no campo da empregabilidade, devido, entre outras razões, à globalização de matriz neoliberal; por outro lado, a competitividade, no mercado de trabalho, gera novas exigências e necessidades, em termos de dinâmicas autoformativas e da necessidade de aprendizagem ao longo da vida. Partindo de uma metodologia baseada em estudo de caso, considerando a escassez de dados empíricos, nesta área, optou-se por privilegiar a recolha de dados baseada na realização de entrevistas, na aplicação de inquéritos por questionário e na pesquisa documental. Para o tratamento do "corpus de dados" que se foi constituindo, ao longo da pesquisa, recorreu-se à técnica de análise de conteúdo e à análise estatística descritiva. A pesquisa empírica teve lugar nas principais instituições de ensino superior que operam na Cidade da Beira, nomeadamente, Universidade Pedagógica de Moçambique, Delegação da Beira, Universidade do Zambeze, Universidade Católica de Moçambique, Universidade Jean Piaget de Moçambique e o Instituto Superior de Ciências e Tecnologias Alberto Chipande, onde participaram 1167 inquiridos. O estudo concluiu que a orientação vocacional e profissional ainda não é suficientemente reconhecida, particularmente no ensino superior. Ainda que, por parte de algumas instituições, já se constate uma preocupação por acompanhar os estudantes no seu processo vocacional e profissional, este acompanhamento ainda se restringe, essencialmente, à sua vertente académica, descurando as outras dimensões, como sejam, a dimensão psicológica, a dimensão auto-formativa, a dimensão empreendedora e a dimensão de aprendizagem ao longo da vida. Por conseguinte, a orientação vocacional e profissional, dentro desta perspectiva holística, advoga por um modelo integrador, onde a preocupação não seja apenas a transição entre o ensino secundário, o ensino superior e
\end{abstract}

o mercado de trabalho, mas se entenda como uma transição "permanente", que capacite os futuros profissionais para apreenderem em contexto e ao longo da vida, considerando os contextos de incerteza e precariedade em que vivemos.

Palavras-Chave: Orientação Vocacional - Orientação Profissional - Modelos de Orientação - Instituições de Ensino.

\begin{abstract}
This article has as its main focus to account of the perceptions of educational stakeholders, in the context of educational institutions (secondary and higher), on the meaning of the vocational and professional orientation. This study was conducted in the city of Beira (Mozambique), involving the main institutions of secondary and higher education institutions. Vocational and professional guidance assumes a significant relevance, considering, on the one hand, the uncertainties and the permanent mobility in the field of employability, due, among other reasons, to the globalization neoliberal matrix; on the other hand, the competitiveness in the labour market, generates new needs in terms of auto-formative dynamics and the need for lifelong learning. Starting from a case study-based methodology, considering the paucity of empirical data, in this area, we decided to focus on the collection of data based on interviews, on the implementation of surveys and on documentary research. For the treatment of the "corpus" that was forming along the research, the technique was used content analysis and descriptive statistics analysis. The empirical research took place in the main institutions of higher education operating in the city of Beira, in particular, pedagogical University of Mozambique, Delegation of Beira, the Zambezi University, Catholic University of Mozambique, Jean Piaget University of Mozambique and the higher Institute of Sciences and technologies Alberto Chipande, attended by 1167 respondents. The study concluded that vocational and professional guidance is not yet sufficiently recognized, particularly in higher education. Even if, by some institutions, where already a concern to follow students in vocational and professional process, this follow-up still limited essentially to its academic, neglecting the other dimensions, such as the psychological dimension, the auto-formative dimension,
\end{abstract}


the entrepreneurial dimension and the dimension of lifelong learning. Therefore, the vocational guidance and professional, within this holistic perspective, advocates for a reseller model, where the concern is not just the transition between secondary education, higher education and the job market, but if you understand how a permanent transition, which empower the future professionals to seize in context and, considering the contexts of uncertainty and insecurity in which we live.

Keywords: Vocational Orientation-career guidanceguidance Models - educational institutions.

\section{Introdução}

No contexto do ensino secundário e superior, a orientação vocacional e profissional assume uma relevância significativa, considerando, por um lado, as incertezas, a precariedade e a mobilidade permanente no campo da empregabilidade, devido à globalização de matriz neoliberal; por outro lado, a competitividade, no mercado de trabalho, gera novas exigências e necessidades, em termos de dinâmicas auto-formativas e da necessidade de aprendizagem ao longo da vida. Desta feita, a orientação vocacional e profissional surge como uma estratégia-chave necessária, no âmbito do ensino secundário e superior, para acompanhar os processos de transição num contexto crucial da vida dos estudantes que tem que ver com a sua transição para o ensino superior ou para a sua inserção social e profissional.

Quando se fala da transição para o ensino superior ou para a vida activa no mercado de trabalho, mais do que uma mera passagem, trata-se, cada vez mais, um processo de tomada de decisões em relação a escolhas sobre instituições a seguir com os estudos, cursos a escolher e tipo de formação a optar, o que faz com que essa decisão seja cada vez mais complexa, obrigando que as entidades envolvidas no processo tenham que optar por uma abordagem multidimensional com uma perspectiva holística e integrada. Portanto, é neste contexto que o presente estudo tem como objectivo central apresentar propostas de modelos de orientação vocacional e profissional nas instituições de ensino secundário e superior na Cidade da Beira, com o intuito de apresentar mecanismos de acompanhar e mediar o percurso no quadro das trajectórias de vida formativa e profissionais dos estudantes, tendo em conta as suas capacidades e habilidades vocacionais, por um lado, as condições disponíveis nas instituições de ensino e as estratégias a seguir, por outro lado.

\section{Orientação Vocacional e Profissional: Conceito e Modelos}

A orientação é um processo que se centra na indicação da "direcção e a configuração tomadas ou a tomar pela existência dos indivíduos em sociedades e, consequentemente, pela própria sociedade. Historicamente, tal orientação mostra-se, independentemente de qualquer intervenção intencional, como resultado da interacção do indivíduo com o respectivo sistema socio-económico-cultural e político, normalmente com os seus sistemas educativos e profissionais" (Campos, 1980, p. 45). Desta feita, percebe-se que a acção orientadora se caracteriza como actividade educativa, planificada, avaliada, compartilhada, grupal, preventiva e integrada no currículo, baseada na abrangência do processo educacional, tendo como base a educação formal, informal e não formal.

Enquanto Freire (1980, p. 27) entende que a acção orientadora é fundamentalmente grupal, destinada a grupos homogéneos em suas necessidades. É compreensiva em relação como seus propósitos e com as distintas áreas de intervenção com a actuação por programas se facilita uma orientação profissional preventiva para o desenvolvimento, Fletcher (1913, citado por Sérgio, 1999) pontua que é preciso compreender a orientação profissional como a selecção da preparação para a colocação na vida laboral. Esta concepção leva-nos a uma reflexão em torno das garantias técnicas que uma orientação pode trazer ao nível de orientação, por sua vez, Super (1976) compreende que a orientação profissional é "O processo mediante o qual se ajuda uma pessoa a desenvolver e aceitar uma imagem completa e adequada de si mesma e de seu papel no mundo do trabalho, pôr a prova este conceito frente a realidade quotidiana e a convertê-lo numa realidade para sua satisfação pessoal e para benefício da sociedade" (Super, 1976, p. 13).

Desta feita, chega-se a constatação de que "a orientação profissional se deve definir como o conjunto de conceitos directivos e de métodos que ajudam para indicar a cada um seu dever de trabalho para o que possui as atitudes e capacidades necessárias e em cujo exercício, consequentemente, tem a possibilidade de obter alternativas até conseguir os melhores resultados para utilidade própria a da mesma sociedade", como aponta Gemelli (1959, p. 36). Nesta senda, Tavares (2009, p.28) refere que "a origem da orientação vocacional está intimamente ligada ao desenvolvimento dos serviços de orientação profissional e educativa. Na década de 50, este tipo de actividade não estava restrita às indicações puramente educativas, mas também abarcavam problemas de ajuste social".

Em termos práticos, juntamente com Fletcher (1913) citado por Rodriguez Moreo (1987, p. 22), a orientação vocacional e profissional pode ser encarada um "processo de selecção e preparação do estudante para a vida laboral". Enquanto isso, Claparède (1992, p. 37) pontua que a orientação vocacional e profissional é um "processo de formação que visa dirigir e guiar o estudante para uma profissão que lhe ofereça mais possibilidades e probabilidades de sucesso, correspondendo às suas atitudes psíquicas e físicas". Desta feita, nota-se que este processo de ensino assenta na tentativa de conhecer o orientando; verificar as aptidões requeridas para uma dada profissão e conhecer o mercado de trabalho disponível.

Existem vários modelos de orientação vocacional desenvolvidos por teóricos ao longo dos tempos. Para Tavares (2009), na sua tese de doutoramento intitulada “Orientação Vocacional e Profissional: Um Estudo 
Sobre Funcionamento das Estruturas de Orientação nas Escolas do Distrito de Braga", defendida na Universidade de Granada, apresenta os seguintes modelos de orientação vocacional e profissional: modelo de couseling, modelo clínico ou modelo de actuação individualizada, modelo de serviços, modelo de programas, modelo de consulta, modelo tecnológico e modelo psicodinâmico. Para Bock (2013), na obra "Orientação Profissional: A Abordagem SócioHistórica" apresenta o modelo do significado das escolhas profissionais, o modelo do trabalho e o modelo de auto conhecimento. Finalmente, Sparta et al. (2006, p. 19-32), no artigo intitulado "Modelos e Instrumentos de Avaliação em Orientação Profissional: Perspectiva Histórica e Situação no Brasil”, publicado pela Revista Brasileira de Orientação Profissional, apresenta o modelo de avaliação psicológica centrado no resultado e o modelo de avaliação psicológica centrado no processo.

Por conseguinte, considerando os vários modelos, aqui brevemente revistos a partir da literatura da especialidade, podemos concluir que a orientação vocacional e profissional assume vários significados, dependente dos pontos de vista convocados espelhos diversos autores e diversas escolas de pensamento. Preconizando um modelo integrador e holístico da chamada "orientação vocacional e profissional", a leitura que procurámos convocar, para interpretar os dados empíricos recolhidos, privilegiou a construção plural de significados tendo em linha de conta as percepções que foram sendo construídas em torno de alguns actores educativos, tanto ao nível do ensino secundário, como do ensino superior.

\section{Metodologia da Pesquisa}

A investigação científica depende de um "conjunto de procedimentos intelectuais e técnicos" (Gil, 1999, p. 26). O estudo apresentado procura dar conta da possibilidade de propor modelos de orientação vocacional e profissional nas instituições de ensino secundário e superior na Cidade da Beira, onde numa primeira aproximação "ao terreno", constatou-se que este campo de intervenção ainda está a dar os seus primeiros passos e nesta fase, os resultados que são apresentados se revestem de um carácter exploratório.

Considerando que a temática em estudo ainda não reúne dados sistemáticos consistentes de estudos realizados, no contexto moçambicano, optou-se pela modalidade de estudo de caso. Para Yin (2001, p. 43), "o estudo de caso é uma estratégia de pesquisa que compreende um método que abrange tudo em abordagens específicas de colectas e análise de dados". Esta metodologia permite um acesso aos contextos naturais para perceber, in loco, a complexidade de um fenómeno. A opção por um estudo de caso nas instituições de ensino superior que operam na Cidade da Beira, justifica-se pelo facto de ser uma oportunidade de verificar-se as práticas de orientação vocacional e profissional por elas realizadas, para a partir daí, propor-se modelos de orientação vocacional e profissional com o foco multidimensional e com uma abordagem holística e integrada.

Participaram, neste estudo exploratório, inquiridos das seguintes instituições: Universidade Pedagógica Delegação da Beira, Universidade Católica, Universidade Zambeze, Universidade Jean Piaget e o Instituto Superior Alberto Chipande. Optou-se por inquirir estudantes que se encontram nos primeiros anos do ensino superior, uma vez que eles representam os que entraram para a universidade, mas são os que acabam de vir das instituições de ensino secundário, o que faz com que as constatações do estudo sirvam para deduzir situações dos dois ciclos formativos, secundário e superior, respectivamente.

Numa primeira aproximação, optou-se por inquirir os estudantes que frequentam os diversos cursos nestas instituições de ensino superior. Para Drever (1995, p. 91), "um questionário permite a recolha de informação estandardizada e todos os inquiridos respondem às mesmas perguntas ao mesmo tempo pelo que permite analisar a necessidade de comparação entre as respostas". Os resultados foram sistematizados e analisados com recursos a programas informáticos de estatística. Finalmente, os dados foram problematizados e analisados, com recurso à técnica de discussão de grupos (Flick, 2005; Sampieri, Collado \& Lucio, 2006).

\section{Pesquisa Empírica: Percepções Sobre Orientação Vocacional e Profissional}

A pesquisa empírica teve lugar nas principais instituições de ensino superior que operam na Cidade da Beira, nomeadamente, Universidade Pedagógica de Moçambique, Delegação da Beira, Universidade do Zambeze, Universidade Católica de Moçambique, Universidade Jean Piaget de Moçambique e o Instituto Superior de Ciências e Tecnologias Alberto Chipande. Participaram do estudo 1167 , onde $31.4 \%$ foram da Universidade Católica, contra $4.9 \%$ da Universidade Jean Piaget, enquanto $30.0 \%$ foram da Universidade Zambeze, contra $15.3 \%$ que foram do Instituto Superior de Ciências e Tecnologias Alberto Chipande e $18.4 \%$ da Universidade Pedagógica, como se pode notar nos dados patentes na tabela, abaixo.

Tabela 1.

Instituição de formação do inquirido

\begin{tabular}{lcc}
\hline \multicolumn{1}{c}{ Instituições de Ensino } & Casos & \% Válida \\
\hline UP & 215 & $18.4 \%$ \\
UNIZAMBEZE & 350 & $30.0 \%$ \\
Universidade Católica & 366 & $31.4 \%$ \\
UNIPIAGET & 57 & $4.9 \%$ \\
ISCTAC & 179 & $15.3 \%$ \\
\hline Total & $\mathbf{1 1 6 7}$ & $\mathbf{1 0 0 \%}$ \\
\hline
\end{tabular}

Dos 1167 casos inquiridos em todas as instituições de ensino superior em estudo, $50 \%$ apontaram que são do sexo masculino, contra $49.5 \%$ que apontaram que são do sexo feminino, enquanto $0.5 \%$ não identificou o seu género. Por sua vez, $72.2 \%$ possuem uma idade compreendida entre 18 e 25 anos, contra apenas $0.3 \%$ que possuem acima de 50 anos, enquanto $16.0 \%$ possui 
uma idade compreendida entre 26 e 35 anos, contra $4.9 \%$ que possui uma idade abaixo de 17 anos e $6.2 \%$ possuem a idade entre 26 e 50 anos. Deste universo, apenas $0.3 \%$ não deu qualquer tipo de resposta em relação a sua faixa etária.

A tabela, abaixo, apresenta as respostas do inquiridos quando questionados sobre qual é área de estudo que se encontra a frequentar, onde nota-se que a maioria dos inqueridos apontou com ciências, como se pode notar nos dados patentes na referida tabela.

Tabela 2

Qual é área de estudo que se encontra a frequentar?

\begin{tabular}{lcc}
\hline \multicolumn{1}{c}{ Áreas de Estudo } & Casos & \% Válida \\
\hline Letras & 428 & $36.7 \%$ \\
Ciências & 649 & $55.6 \%$ \\
Artes & 6 & $0.5 \%$ \\
Sem resposta & 84 & $7.2 \%$ \\
\hline Total & $\mathbf{1 1 6 7}$ & $\mathbf{1 0 0 \%}$ \\
\hline
\end{tabular}

De acordo com os dados patentes na tabela, acima, nota-se que $55.6 \%$ dos inquiridos apontou que frequenta cursos da área das ciências, contra apenas $0.5 \%$ que frequentam as belas artes, enquanto isso, $36.7 \%$ apontou que frequentam cursos relacionados com letras e ciências sociais. Importa referir que $7.2 \%$ dos inquiridos não deu qualquer tipo de resposta. Quando questionados sobre a área de estudo que mais gostava no ensino pré-universitário, as respostas entraram em consonância com as áreas de estudo em que se encontram a frequentar com $52.4 \%$ e apontou que gostava de ciências exactas, contra $0.6 \%$ que gostava de belas artes e $40.0 \%$ que gostava da área das letras e Ciências Sociais.

Um elemento importante no processo de formação, com vista a arcar o sucesso escolar e uma possível inserção positiva no mercado de trabalho é formar-se na área em que o estudante têm vocação e inclinação. Não basta querer frequentar um curso, mas sim há um conjunto de condições e determinantes para que o aluno goste do curso que frequenta e esse é um dos aspectos determinantes para o sucesso formativo.

A tabela, abaixo, apresenta as respostas dos inqueridos quando questionados se os cursos que frequentavam eram os que sempre desejaram desde o período do ensino secundário. Surpreendentemente, a maior deu uma resposta positiva.

Tabela 3

Encontra-se a frequentar o curso que sempre desejou?

\begin{tabular}{lcc}
\multicolumn{1}{c}{ Respostas } & Casos & \% Válida \\
\hline Sim & 856 & $73.4 \%$ \\
Não & 305 & $26.1 \%$ \\
Sem resposta & 6 & $0.5 \%$ \\
\hline Total & $\mathbf{1 1 6 7}$ & $\mathbf{1 0 0 \%}$ \\
\hline
\end{tabular}

De acordo com os dados patentes na tabela, acima, a maioria dos inquiridos $(73.4 \%)$ encontra-se a frequentar o curso que sempre desejou, contra $26.1 \%$ dos mesmos que não frequentam os cursos desejados, mas um conjunto de condições e razões de força maior fizeram com que eles adoptassem os cursos que frequentam. Do universo total dos inquiridos, apenas $0.5 \%$ não deram qualquer tipo de resposta. Esses dados são encorajadores, porque dão a ideia de que se os estudantes frequentam cursos desejados, eles possuem alguma inclinação ou vocação para a área, o que pode facilitar em muito o processo de orientação vocacional e profissional, com vista a despontar e desenvolver as habilidades e capacidades que eles possuem na área, com vista a facilitar o processo formativo a sua inserção no mercado de trabalho, com vista a alcançarse o sucesso profissional.

A tabela, abaixo, apresenta as respostas dos inquiridos quando questionados sobre quais são as razões e critérios da escolha do curso que frequenta, onde a maioria dos mesmos apontou para critérios pessoais, o que desafia as instituições de ensino e os profissionais da área de orientação a ter uma abordagem vocacional e profissional com vista a ajudar os estudantes a tomarem as decisões para seguir uma área de formação, tendo em conta as suas habilidades e capacidades, visto que não basta querer frequentar um determinado curso, tendo em conta questões pessoais, uma vez que pode enfrentar desafios que podiam ser muito bem ultrapassados a partir de uma abordagem decisória baseada nas habilidades vocacionais de cada um.

Tabela 4.

Quais são as razões e critérios da escolha do curso que frequenta?

\begin{tabular}{lcc}
\hline $\begin{array}{c}\text { Critérios de Escolha } \\
\text { do Curso }\end{array}$ & Casos & \% Válida \\
\hline Pessoais & 485 & $41.6 \%$ \\
Familiares & 85 & $7.3 \%$ \\
Sociais/Económicas & 110 & $9.4 \%$ \\
Vocacionais & 179 & $15.3 \%$ \\
Profissionais & 244 & $20.9 \%$ \\
Obrigações & 19 & $1.6 \%$ \\
Vocacionais e & 2 & $0.2 \%$ \\
Profissionais & 16 & $1.4 \%$ \\
Pessoais e Familiares & 27 & $2.3 \%$ \\
Sem Resposta & $\mathbf{1 1 6 7}$ & $\mathbf{1 0 0 \%}$ \\
\hline \multicolumn{1}{c}{ Total } & &
\end{tabular}

De acordo com os dados patentes na tabela, acima, constata-se $41.6 \%$ dos inquiridos relevam os critérios pessoais para escolher o curso que frequenta, contra apenas $0.2 \%$ que usaram questões vocacionais e profissionais para escolher um curso, enquanto $20.9 \%$ usaram critérios somente profissionais, contra $1.4 \%$ que foram influenciados por questões pessoais e familiares. Por seu turno, $15.3 \%$ usaram critérios somente vocacionais, contra $1.6 \%$ que frequentam os cursos por obrigação, enquanto $9.4 \%$ foram forçados a frequentar os cursos por pressões sociais e económicas, contra $7.3 \%$ que foram forçados pelos familiares. Portanto, pode-se notar que as questões pessoais que podem ser de várias ordens são o critério dominante 
para a escolha dos cursos da maioria dos inquiridos que se encontram a frequentar diversos cursos nas instituições de ensino superior que operam na Cidade da Beira.

Uma das questões que norteou o estudo está relacionada com as diversas entidades que se envolveram no processo de escolha e tomada de decisão dos estudantes na escolha do curso a frequentar no nível superior da sua formação. Quanto questionados sobre quem os ajudou no processo de escolha do curso que se encontram a frequentar, a maioria apontou para familiares e um número considerável respondeu que não teve qualquer tipo de ajuda nesse sentido.

Tabela 5

Quem o ajudou no processo de escolha do curso que se encontra a frequentar?

\begin{tabular}{lcc}
\hline \multicolumn{1}{c}{ Entidade de Ajuda } & Casos & \% Válida \\
\hline Familiares & 611 & $52.4 \%$ \\
Familiares e Professores & 6 & $0.5 \%$ \\
Professores & 61 & $5.2 \%$ \\
Palestras & 96 & $8.2 \%$ \\
Gabinetes de Apoio & 37 & $3.2 \%$ \\
Orientações feitas nas & 82 & $7.0 \%$ \\
escolas ou equipe de & & \\
universidades & & \\
Ajuda de Amigos & 30 & $2.6 \%$ \\
Publicidade & 6 & $0.5 \%$ \\
Sem Qualquer Ajuda & 179 & $15.3 \%$ \\
Sem Resposta & 59 & $5.1 \%$ \\
\hline Total & $\mathbf{1 1 6 7}$ & $\mathbf{1 0 0 \%}$ \\
\hline
\end{tabular}

De acordo com os dados patentes na tabela, acima, $52.4 \%$ apontou que teve ajuda dos familiares, no processo de decisão da escolha do curso a frequentar no ensino superior, contra apenas $3.2 \%$ que para apoio de gabinetes ou departamento de apoio nas instituições de ensino secundário onde estudava ou universitário onde pretendia ingressar. Enquanto isso, 15.3\% apontou que não teve qualquer tipo de ajuda formal e institucional no processo de escolha do curso que deveriam seguir no ensino superior, o que fez com que a decisão fosse muito pessoal, tendo em conta as condições, contingências e contexto em que se encontrava, sobretudo em termos económicos e financeiros para custear as despesas de formação.

Tendo em conta os dados patentes na tabela, acima, pode-se notar que há pouca influência de instituições e mecanismos formais de orientação vocacional e profissional no processo de escolha do curso a seguir no ensino superior, o que faz com que as pessoas sigam áreas de formação tendo em conta a influência de familiares, amigos e próximos que relatam sobre determinados cursos e determinadas instituições de ensino superior. A influência do professor e de palestras ainda é muito baixa no processo de tomada de decisão dos estudantes sobre os cursos a seguir, com $5.2 \%$ para o primeiro e $8.2 \%$ para o segundo. Para além disso, as orientações feitas nas escolas por equipas de instituições de ensino superior também é muito baixa, com $7.0 \%$ o que desafia as instituições a ter mais contacto com os estudantes, com vista a auxilia-los no processo de tomada de decisão sobre o curso a seguir no ensino superior.

Quando questionados sobre que tipo de apoio tiveram na instituição onde frequentaram o ensino pré - universitário, a maioria dos inquiridos apontou para a realização de palestras sobre vantagens e desvantagens do curso e um número significante apontou que não recebeu qualquer tipo de apoio pelas suas escolas secundárias, com vista a decidir a instituição e o curso a seguir no nível superior, como se pode notar no conjunto de dados patentes na tabela, abaixo.

Tabela 6.

Que tipo de apoio teve na instituição onde frequentou o ensino pré - universitário?

\begin{tabular}{lcc}
\hline \multicolumn{1}{c}{ Tipo de Apoio } & Casos & \% Válida \\
\hline Gabinetes de & 98 & $8.4 \%$ \\
Aconselhamento & & \\
Seminário de Curso & 133 & $11.4 \%$ \\
Palestras Sobre vantagens & 348 & $29.8 \%$ \\
e desvantagens do Curso & & \\
Salas de Estudo & 271 & $23.2 \%$ \\
Sem apoio & 186 & $15.9 \%$ \\
Sem Resposta & 131 & $11.2 \%$ \\
\hline Total & $\mathbf{1 1 6 7}$ & $\mathbf{1 0 0 \%}$ \\
\hline
\end{tabular}

De acordo com os dados patentes, na tabela, acima, pode-se notar que $29.8 \%$ dos inquiridos referiu que as escolas secundárias realizavam palestras sobre vantagens e desvantagens do curso, contra apenas $8.4 \%$ que apontou para a existência de gabinetes de apoio e aconselhamento vocacional e profissional, enquanto 23.2\% apontou para a disponibilização de salas de estudo, contra $11.4 \%$ que apontou a realização de seminários sobre cursos. Por seu turno, $15.9 \%$ respondeu que não recebeu qualquer tipo de apoio das suas escolas para decidir sobre cursos a seguir no ensino superior e $11.2 \%$ não deu qualquer tipo de resposta.

Um dos aspectos importantes no processo de orientação académica, vocacional e profissional tem a ver com a inserção profissional dos formados, onde o mesmo desempenhará a suas carreiras profissionais. Esta é uma das tarefas das instituições de ensino, que por via de acordos, protocolos e outros mecanismos de cooperação pode oferecer um conjunto de facilidades para que os formados possam se inserir facilmente no mercado de trabalho. Quando questionados obre que mecanismo de apoio para inserção no mercado de trabalho a instituição de ensino proporciona, a maioria apontou para os estágios profissionais. 
Tabela 7.

Que mecanismo de apoio com vista a inserção no mercado de trabalho a instituição de ensino proporciona?

\begin{tabular}{lcc}
\hline \multicolumn{1}{c}{$\begin{array}{c}\text { Mecanismos de } \\
\text { Apoio }\end{array}$} & Casos & \% Válida \\
\hline Palestras & 300 & $25.7 \%$ \\
Simulações & 90 & $7.7 \%$ \\
Empresariais & & \\
Seminários & 98 & $8.4 \%$ \\
Visitas de Estudo & 92 & $7.9 \%$ \\
Estágios Profissionais & 502 & $43.0 \%$ \\
Palestras, Simulações & 12 & $1.0 \%$ \\
Empresariais, Estágios & & \\
Profissionais & & \\
Sem Resposta & 73 & $6.3 \%$ \\
\hline Total & $\mathbf{1 1 6 7}$ & $\mathbf{1 0 0 \%}$ \\
\hline
\end{tabular}

De acordo com os dados patentes na tabela, acima, pode-se notar que a maioria das instituições de ensino superior proporciona estágios profissionais (43.0\%) como mecanismos de apoio com vista a inserção laboral dos seus formandos no mercado de trabalho, contra apenas $1.0 \%$ que faz a combinação de palestras, simulações empresariais, estágios profissionais, enquanto $25.7 \%$ realiza somente palestras, contra $7.7 \%$ que realiza simulações empresariais e $8.4 \%$ realiza seminários. Deste universo, $6.3 \%$ não deu qualquer tipo de resposta a pergunta. Portanto, constata-se que as instituições de ensino usam uma abordagem unidimensional centrada numa mesma estratégia e a abordagem multidimensional combinando palestras, simulações empresariais, estágios profissionais ainda é muito pouco usada. Todavia, essa abordagem multidimensional pode trazer bons resultados, porque combina várias estratégias que pode ser usadas para situações e contextos muito específicos.

Finalmente, quando questionados sobre que mecanismos podem ser adoptados para $o$ melhoramento do processo de integração no ensino superior, a maioria dos inquiridos respondeu que era importante que se concentrassem na realização frequente de palestras e visitas estudantis a instituições, para explicar o processo de integração, por um lado, e dar a oportunidade de ter contacto com o mercado de trabalho, por outro lado, como se pode notar nos dados patentes na tabela, abaixo.

Tabela 8.

Que mecanismos podem ser adoptados para o melhoramento do processo de integração no ensino superior?

\begin{tabular}{|c|c|c|}
\hline Mecanismos & Casos & \% Válida \\
\hline Testes Psicotécnicos & 234 & $20.1 \%$ \\
\hline Palestras sobre os cursos & 462 & $39.6 \%$ \\
\hline $\begin{array}{l}\text { Visitas Estudantis a } \\
\text { Instituições }\end{array}$ & 381 & $32.6 \%$ \\
\hline $\begin{array}{l}\text { Palestras sobre os cursos e } \\
\text { visitas estudantis a } \\
\text { instituições }\end{array}$ & 36 & $3.1 \%$ \\
\hline Sem Resposta & 54 & $4.6 \%$ \\
\hline Total & 1167 & $100 \%$ \\
\hline
\end{tabular}

De acordo com os dados patentes na tabela, acima, pode-se constatar que quando questionados sobre que mecanismos podem ser adoptados para o melhoramento do processo de integração no ensino superior, 39.6\% apontou para a necessidade de realização de palestras que expliquem sobre os conteúdos e saídas profissionais dos cursos, contra apenas $3.1 \%$ que apontou para a necessidade de se fazer a combinação de palestras sobre os cursos e visitas estudantis a instituições. Por seu turno, $32.6 \%$ apontou para a realização de visitas estudantis à instituições, contra $20.1 \%$ que apontou para a realização de testes psicotécnicos e apenas $4.6 \%$ dos inquiridos não deu qualquer tipo de resposta.

\section{Considerações Finais}

No processo de orientação vocacional e profissional em Moçambique, o papel dos atores educativos estatais e não estatais deve ser desempenhado dentro de uma perspectiva holística, advogado por um modelo integrador, onde a preocupação não deve ser apenas em questões relacionadas com a transição entre o ensino secundário, o ensino superior e o mercado de trabalho, mas deve-se entender como uma transição "permanente", que capacite os futuros profissionais para apreenderem em contexto e ao longo da vida, considerando os contextos de incerteza e precariedade em que vivemos.

Os actores estatais e não estatais com interesses na melhoria da qualidade de formação dos estudantes envolvidos num processo formativo e a sua integração futura no mercado de trabalho e a sua realização na carreira profissional podem desempenhar um papel relevante no processo. Portanto, trata-se de cum conjunto de intenções, acções e actividades que envolvem acompanhamento do estudo, tutoria, até à organização de programas de transição para a vida laboral activa. É neste ponto onde se distingue da orientação académica e profissional que se centra no fornecimento de habilidades aos estudantes, para responderem positivamente às exigências da sua formação, num contexto específico.

Tendo em conta as entrevistas cedidas e o material sistematizado constata-se que na maior parte das instituições de ensino superior em Sofala não há orientação vocacional, mas sim orientação académica e profissional, que até é, em muitas vezes muito lacónica e deficitária. Desta feita, para uma melhor inserção no mercado laboral dos estudantes do ensino superior, a formação deve ser baseada numa orientação académica e profissional, mas, também, alicerçada na dimensão vocacional e profissional dos estudantes de uma forma integrada e holística. Por conseguinte, para além deste acompanhamento pedagógico e de inserção profissional (mediante a prática de estágios), a orientação deve, também, privilegiar outras dimensões, mais de carácter vocacional e auto-formativo: capacitar os estudantes para apreenderem em contexto e numa dinâmica de aprendizagem ao longo da vida. Isto requer que as instituições educativas invistam num 
modelo de ensino e de orientação centrado no perfil de competências a adquirir no processo formativo.

Não obstante ao facto da maioria dos inquiridos estarem a frequentar cursos que sempre desejaram, as instituições de ensino secundário e superior têm a tarefa de proporcionar um conjunto de mecanismos para auxiliar o processo de orientação vocacional e profissional dos estudantes, com vista a despontar e desenvolver as habilidades e capacidades que eles possuem, como forma de facilitar o processo formativo e a sua inserção no mercado de trabalho, num contexto de crescente globalização e, por conseguinte, num contexto de crescente incerteza e precariedade. Fazer face a este contexto, significa perspectivar a orientação académica dentro de um marco integrador e holístico.

As questões pessoais são o critério mais dominante para a escolha dos cursos que os estudantes se encontram a frequentar. Este aspecto transparece a ideia de que há pouca influência de instituições e mecanismos formais de orientação vocacional e profissional no processo de escolha de que curso se pode seguir no ensino superior, o que faz com que as pessoas sigam áreas de formação tendo em conta a influências pessoais, familiares, amigos e de próximos. Neste contexto, a influência das instituições formais, o papel do professor, palestras, seminários, psicólogos e gabinetes de orientação vocacional e profissional ainda é muito baixa. Desta feita, as instituições formais são desafiadas a envolverem-se mais no processo de tomada de decisão dos estudantes, investindo mais na sua capacidade de aprendizagem, face a uma multiplicidade de "transições" que ocorrem ao longo da vida e não apenas, em determinadas fases da vida académica.

Um dos aspectos importantes no processo de orientação académica, vocacional e profissional tem a ver com a inserção profissional dos formados, onde o mesmo desempenhará a sua carreira profissional. Esta é uma das tarefas das instituições de ensino, que por via de acordos, protocolos e outros mecanismos de cooperação pode oferecer um conjunto de facilidades para que os formados possam inserir-se, facilmente no mercado de trabalho. Desta feita, há necessidade de melhorar-se a integração dos estudantes por via da realização de palestras que expliquem os conteúdos e saídas profissionais dos cursos, bem como a realização de seminários e visitas estudantis a instituições, bem como a realização de testes psicotécnicos, dando oportunidade para a realização de actividades multidimensionais com uma abordagem holística e integrada da orientação vocacional e profissional.

A orientação vocacional e profissional, no contexto do ensino secundário e superior, torna-se numa ferramenta fundamental para que a universidade desempenhe, de forma responsável e proveitosa, o seu papel no quadro dos processos de transição dos estudantes para a vida activa e profissional ou para o mercado do trabalho, de modo a responder às demandas e às exigências da sociedade actual que tende a tornar-se, cada vez mais, global e, consequentemente, mais precária, em matéria de empregabilidade. Neste contexto, os resultados produzidos, neste estudo, indicam que o modelo de orientação vocacional e profissional, que as instituições devem promover, deve privilegiar uma abordagem integradora e holística, isto é, uma abordagem que perspective orientação académica no quadro de um desenvolvimento pessoal, social e profissional e numa dinâmica de auto-formação narrativa e identitária (Canastra, 2007; Cochran, 1997). Portanto, o papel das instituições educativas não deve cingir-se à componente meramente académica, mas privilegiar uma abordagem formativa onde o estudante se torne o sujeito do seu processo vocacional e profissional.

Portanto, pontua-se aqui os atores educativos estatais e não estatais têm um papel determinante para que a orientação vocacional e profissional assuma uma relevância significativa para se fazer face às incertezas e a mobilidade permanente no campo da empregabilidade, devido, entre outras razões, à globalização de matriz neoliberal, por um lado e, por outro lado, a competitividade, no mercado de trabalho, gera novas exigências e necessidades, em termos de dinâmicas auto-formativas e da necessidade de aprendizagem ao longo da vida, em Moçambique. Os resultados apresentados pelo estudo pontuam que a orientação vocacional e profissional ainda não é suficientemente reconhecida, particularmente no ensino secundário e superior, em Moçambique. Por conseguinte, avança-se aqui com a ideia de que a orientação vocacional e profissional, deve ser levada a cabo dentre de uma perspectiva holística, advogando um modelo integrador, onde a preocupação não sejam apenas na transição entre o ensino secundário e o ensino superior e o mercado de trabalho, mas se entendam como uma transição "permanente", que capacite os futuros profissionais moçambicanos para apreenderem em contexto e ao longo da vida, considerando os contextos de incerteza e precariedade em que vivemos.

\section{Referências Bibliográficas}

Bock, S.D.(2013). Orientação Profissional: A Abordagem Sócio-Histórica. São Paulo: Editora Cortez.

Canastra, F. (2007). O perfil do formativo-profissional do educador social:: um estudo a partir das narrativas experiências de autoformação. Lisboa: Universidade Aberta.

Claparèdes, E. (1992). Orientação Vocacional: Seus Problemas e Métodos. Madrid: Edições dela Lectura.

Cochran, L. (1997). Career counseling: A narrative approach. Thousand Oaks, CA: Sage Publications.

Drever, E. (1995). Using Semi-Structured Interviews in Small-Scale Research, Scottish Council for Research in Education, London.

Flick, U. (2005). Métodos Qualitativos na Investigação Científica. Lisboa: Monitor.

Gemilli, A. (1959). Orientação Profissional. Madrid: Editorial Razón.

Gil, A. (2008). Método e Técnicas de Pesquisa Social. São Paulo: Editora Atlas S.A. 
Sampieri, R.H., Collado, C. F. \& Lucio, B. (2003). Metodologia de Pesquisa (3. Ed.). São Paulo: Editora Mc Graw - Hill.

Sparta, M., et al. (2006). Modelos e Instrumentos de Avaliação em Orientação Profissional: Perspectiva Histórica e Situação no Brasil. Revista Brasileira de Orientação Profissional, 2006, 7 (2), PP. 19 - 32.

Tavares, V. L. (2009). Orientação Vocacional e Profissional: Um Estudo Sobre o Funcionamento das Estruturas de Orientação nas Escolas do Distrito de Braga. Granada: Editorial de la Universidade de Granda.

Yin, R. (2001). Estudo de Caso: Planeamento e Método ( $2^{\mathrm{a}}$ Ed.). Porto Alegre: Editora Bookman. 